\title{
O JORNAL DAS SENHORAS E A BUSCA PELA EMANCIPAÇÃO MORAL E INTELECTUAL DA MULHER BRASILEIRA
}

\author{
Itiana Daniela Kroetz ${ }^{1}$ \\ Eunice T. Piazza Gai
}

\begin{abstract}
Resumo: No século XIX a educação destinada às mulheres era quase nula e poucas sabiam ler. Se ler já era considerado perigoso, escrever era muito pior, já que assim as mocinhas podiam grafar bilhetes aos seus pretendentes, ameaçando a paz e a integridade da família patriarcal e pondo em risco a autoridade paterna. Pior ainda era a mulher escrever e publicar textos assinados, isso era considerado um atentado à honra, já que tanto o nome da mulher, quanto sua pessoa, devia se manter dentro do lar. O que se esperava do sexo feminino era que fossem boas esposas, mães e donas de casa. É nesse momento histórico que surge o Jornal das Senhoras, o que parece ser a primeira publicação brasileira direcionada ao público feminino e escrita por mulheres. O principal objetivo dessa revista era promover a emancipação moral e intelectual da mulher. Porém, não podemos ver a emancipação feminina com um olhar contemporâneo, pois as editoras do Jornal das Senhoras entendiam essa emancipação como sendo a ilustração da mulher. Desse modo, esse estudo pretende apresentar uma contextualização histórica da condição feminina no Brasil, no século XIX, bem como um contraste entre a mulher brasileira e a mulher europeia daquele período. Esse trabalho também trata do surgimento da imprensa feminina no Brasil e caracteriza o Jornal das Senhoras a partir dos textos publicados nessa revista. E é através desses textos que podemos entender $o$ que as editoras desse periódico entendiam por emancipação moral e intelectual da mulher.
\end{abstract}

Palavras-chave: Jornal das Senhoras. Século XIX. Periódicos. Mulher.

Abstract: In the nineteenth century the education aimed at women was almost nil and few could read. If reading was considered dangerous, writing was much worse, since the girls could write letters to their suitors, threatening the peace and the integrity of the patriarchal family and endangering parental authority. Even worse was the woman write and publish signed texts, it was considered an affront to the honor, since both the woman's name, as his person, should remain within the home. What was expected from women was that they should be good wives, mothers and homemakers. It is in this historical moment that arises the Jornal das Senhoras, it seems to be the first Brazilian publication aimed at women and written by women. The main objective of this magazine was to promote the moral and intellectual emancipation of women. However, we can not see female emancipation with a contemporary look, because the

\footnotetext{
${ }^{1}$ Mestranda em Letras da UNISC. Bolsista FAPERGS. Orientadora Prof. a . Dra . Eunice T. Piazza Gai.

${ }^{2}$ Doutora em Linguística e Letras pela PUCRS. Docente e Coordenadora do Programa de Pósgraduação - Mestrado em Letras da UNISC.
} 
publishers of the Jornal das Senhoras understood this emancipation as the illustration of woman. Thus, this study aims to present a historical overview of women's condition in Brazil, in the nineteenth century, as well as a contrast between Brazilian woman and European woman of that period. This research also deals with the emergence of women's press in Brazil and features the Jornal das Senhoras from the texts published in this magazine. It is through these texts that we can understand what the editors of this periodical meant by moral and intellectual emancipation of woman.

Keywords: Jornal das Senhoras. Nineteenth century. Periodicals. Woman.

\section{A CONDIÇÃO FEMININA NO BRASIL, NO SÉCULO XIX: CONTEXTUALIZAÇÃO HISTÓRICA}

No início do século XIX, a condição da mulher podia ser comparada à de escrava. As mulheres raramente podiam sair sozinhas para ir à igreja ou visitar seus parentes. Grande parte do tempo, elas passavam dentro de casa, vestidas em camisolões, entretidas com as suas mucamas.

De acordo com Machado (2001, p. 255), a rua e as seduções que ela trazia podiam ser observadas apenas pelas venezianas das janelas. Desse modo, o que restava ao sexo feminino era ficar em casa conversando e sonhando, ou tocando piano, já que poucas sabiam ler, tornando a situação da mulher ainda pior.

Ler era considerado perigoso para as mulheres porque "ainda vigorava a mentalidade de que letras e tretas só serviam para atrapalhar a mulher. Se fosse analfabeta, ótimo. Para as que aprendiam a ler, muitas delas contrariando a orientação doméstica, bastava a leitura do missal” (Machado, 2001, p. 256). Se ler já era considerado perigoso, escrever era muito pior, já que assim as mocinhas podiam grafar bilhetes aos seus pretendentes, ameaçando a paz e a integridade da família patriarcal e pondo em risco a autoridade paterna. Pior ainda era a mulher escrever e publicar textos assinados, isso era considerado, nas palavras de Machado (2001, p. 256), um atentado à honra, já que tanto o nome da mulher, quanto sua pessoa, devia se manter dentro do lar.

Muitos depoimentos de autores que estiveram pelo Brasil no século XIX, descrevem a carência de instrução das mulheres, destacando a ignorância, má 
aparência e frivolidade que predominava entre elas. Um desses autores foi John Luccock que viveu no Brasil entre 1808 e 1818. Em um de seus registros, ao qual temos acesso na obra de Lajolo e Zilberman, ele relata os limites da alfabetização feminina: "Estava assentado que o saber ler para elas não deveria ir além do livro de rezas, pois que isso lhes seria inútil, nem tão pouco se desejava que escrevessem a fim de que não fizessem, como sabiamente se observava, um mau uso dessa arte" (Luccock apud Lajolo e Zilberman, 1998, p. 241).

Muitos autores daquele período criticavam a demora que as mulheres sofriam para integrarem-se ao horizonte da cultura elevada, eles também criticavam as leituras que eram destinadas ao público feminino, desaprovando desse modo, a tendência de as mulheres lerem o que eles chamavam de "romances açucarados" e folhetins tolos. De acordo com Lajolo e Zilberman (1998, p. 245), essas afirmações críticas mostram que "o universo de leitura da mulher brasileira é dos mais restritos, no que, aliás, se afina bastante à sociedade em que vive. Iletrada na maioria dos casos, a mulher brasileira faz parte de um mundo para o qual o livro, a leitura e a alta cultura não parecem ter maior significado".

\section{CONTRASTES ENTRE A CONDIÇÃO DA MULHER BRASILEIRA E A CONDIÇÃO DA MULHER EUROPEIA}

Dois fatores que contribuíram para a formação do público leitor feminino na Europa, e que foram responsáveis pela grande quantidade de mulheres romancistas na Inglaterra, foram, de acordo com Meyer (1993, p. 47), as transformações ocasionadas pela Revolução Industrial e a constituição de uma classe média. Meyer (1993, p. 48) explica que a novidade dos artigos manufaturados e comercializados no mercado dispensou as mulheres de várias tarefas domésticas. A família extensa aos poucos é substituída pela união conjugal, na qual a valorização do amor e a livre escolha se torna uma consequência, mesmo que ainda vinculada a interesses financeiros. Como resultado disso, aumenta o número de mulheres excluídas da proteção da grande família, forçadas a procurarem sozinhas o seu sustento em virtude da 
dificuldade em arranjar o aspirado casamento. De acordo com Meyer (1993, p. 48), esse novo lazer, que é a leitura, adquirido pelas mulheres, é o que provoca a ascensão desse emergente público leitor, o qual aprecia o gênero mais fácil da ficção em prosa devido à sua cultura incipiente. Desse modo, por volta de 1740, surge na Inglaterra a Circulating Library, que permitia o aluguel do livro. O gabinete de leitura é adotado mais tarde pela França, o que depois é introduzido também aqui no Brasil pelos primeiros livreiros, especialmente os de origem francesa.

Meyer (1993, p. 48) elucida que as mulheres inglesas passaram a não ser mais somente consumidoras das editoras de então, mas também fornecedoras de romances, principalmente para a Minerva Press, da Inglaterra, pois elas eram conhecedoras do gosto por esse novo gênero literário. Trabalhar para essa editora era, para as mulheres que necessitavam lutar pela sua sobrevivência, um modo de garantir o seu sustento. Por isso, de acordo com Meyer (1993, p. 48), muitas autoras se sujeitavam a escrever segundo temas e títulos indicados, e para isso nem era necessário ter muita imaginação, de tão redundante que era o modelo sempre oferecido. Meyer (1993, p. 49) afirma que essas mulheres leitoras e mulheres escritoras, que se enquadravam no âmbito das mulheres comuns, nem sempre conheciam a segurança de um lar e estavam, muitas vezes, entregues aos perigos da Londres de então. Mas, segundo Meyer (1993, p. 49) foram essas mulheres comuns, noveleiras pouco significantes, que com certeza abriram o caminho para as escritoras fora do comum, como por exemplo, Jane Austen, Virginia Woolf, Charlotte Brontë e George Eliot.

Essas romancistas, como explica Meyer (1993, p. 58), estando conscientes da dimensão e das poucas letras de seu público, assim como das suas também, escreviam unicamente com seu instinto e com sua sensibilidade, que era a palavra-chave daquele tempo. Os seus romances eram "um misto de sensibilidade, sentimentalismo, moralismo didático, moral e recato, que continuam a imperar mesmo quando se instalam suspenses, sustos e sadismos dos vilões do romance gótico" (Meyer, 1993, p. 60). Tudo isso era regado a muitas lágrimas, em virtude dos temas recorrentes: "educação, criação de filhos, amor entre religiosos (conflito ou sátira), pesado destino da 
mulher casada, drama das solteironas, sofrimento da governanta, necessidade de princípios (Jane Eyre), expectativas e imprescindível virtude das mocinhas casadoiras, a young lady" (Meyer, 1993, p. 60).

Todo esse processo, ilustrado acima, pelo qual passou a mulher europeia, principalmente a mulher inglesa, demorou a chegar em terras de língua portuguesa. Lajolo e Zilberman (1998, p. 238) explicam que em 1740 verificam-se sinais de mudanças, sendo uma dessas mudanças a publicação do Verdadeiro método de estudar, de Luiz Antônio Verney, o qual foi editado na Itália em 1746. Segundo Lajolo e Zilberman (1998, p. 238), Verney reúne e difunde as novas ideias, as quais foram adotadas durante o governo do Marquês de Pombal, comprometido em estimular o sistema capitalista e em fortalecer a classe burguesa. Verney defende a necessidade de se instruírem as mulheres, argumentando que, como mães de família são as primeiras mestras nos primeiros anos de vida de seus filhos.

Tendo em vista consolidar suas ideias e afirmando ser inspirado em Fénelon e outros filósofos, Verney recomenda um currículo que inclui "estudos de religião, história, economia doméstica, trabalhos manuais e prendas de salão, visando formar tanto ética, como praticamente a mulher e preparando-a para enfrentar os encargos do lar e da vida em sociedade, sendo este o âmbito da esfera pública que Ihe é facultado." (Verney apud Lajolo e Zilberman, 1998, p. 239). Porém, de acordo com Lajolo e Zilberman (1998, p. 239), quando morre D. José, em 1777, cai Pombal e, junto com ele, os projetos de modernização de Portugal. Com isso, também fracassa a reforma educacional, estendendo-se o período de atraso daí resultante no Brasil, ao longo dos séculos XVIII e XIX, como podemos perceber através do testemunho de estrangeiros e brasileiros, trazendo reais consequências ao sistema literário.

\section{O SURGIMENTO DA IMPRENSA FEMININA BRASILEIRA}

A partir de 1840 a mulher brasileira começa a alcançar vitórias notáveis para abrandar a sua condição quase servil. Uma dessas vitórias, como explica Machado (2001, p. 256), foi a abertura das janelas da casa patriarcal. Podendo parar à janela e observar a vida do lado de fora, as jovens podiam namorar 
quem quisessem, tramar fugas com seus amados e adquirirem forças e astúcias para resistir às imposições paternas.

$\mathrm{Na}$ Corte, aumenta o número de escolas para meninas, que de acordo com Machado (2001, p. 256), não era mais um privilégio das moças aristocratas endinheiradas. Algumas dessas escolas eram excelentes, porém, a maioria era bastante deficiente, ensinando um pouco de comportamento social e um francês cambaleante. Nas palavras de Machado (2001, p. 256), essas escolas "preparavam as moças para a vida dos salões, despertavam o interesse pela poesia e a curiosidade pelo romance, porém nada mais ofereciam". De acordo com Teles (1999, p. 27), em vez da instrução propriamente dita, como escrita, leitura e contas, a principal característica dessas escolas femininas era a preparação para as atividades do lar, como, por exemplo, os trabalhos de agulha. Em aritmética, às meninas cabia somente o aprendizado das quatro operações, pois se pensava que para nada lhes serviria o conhecimento da geometria. Teles (1999, p. 28) ainda explica que o número de escolas para meninas era muito menor que o número de escolas para meninos. No Rio de Janeiro, na metade do século XIX, existiam 17 escolas primárias para meninos e apenas nove para meninas. Esse fator demonstra a discriminação da mulher em relação à educação.

Podendo passar alguns momentos fora do ambiente doméstico, longe da vigilância absoluta do pai e do marido, Bicalho (1989, p. 82) esclarece que foi intensificada a presença da mulher no espaço público das ruas, dos cafés, dos teatros, dos bailes e demais acontecimentos da vida social. Esse contato com o exterior, sobretudo através do consumo de bens culturais, como a imprensa, a literatura e o teatro, transformou não unicamente as condições materiais da vida feminina, mas fez com que as mulheres desenvolvessem novos ideais e novas aspirações.

Com a alfabetização feminina, Machado (2001, p. 257) esclarece que aumentou o número de jornais, bem como o de suas tiragens. Também surgiram as primeiras seções voltadas especialmente para o público feminino, como era o caso do romance folhetim.

Nas palavras de Bicalho (1989, p. 83), essa grande quantidade de jornais e revistas dedicados à família e à mulher, surgidos em meados do 
século XIX, dividiram com o livro o espaço das cestas de costura. Porém, esses periódicos não apenas disseminaram os romances do período sob a forma de folhetins, mas ao serem dirigidos à família e principalmente à mulher, também tornaram possível o desenvolvimento de um espaço cultural, "no qual a subjetividade originada na esfera íntima da família foi cada vez mais tematizada, permitindo um processo vivo de lluminismo de um público feminino que lê e comenta tudo isso (e) tem aí a si mesmo como tema" (Bicalho, 1989, p. 84).

A principal reivindicação dessa nascente imprensa feminina era a educação ou instrução da mulher, instrumento imprescindível para a sua racional emancipação.

Essa nova identidade da mulher, explica Bicalho (1989, p. 85) estava calcada na valorização da maternidade, pois a principal artimanha do discurso dos reformadores sociais do século XIX era a de que se constituía como dever materno, a primeira educação dos filhos no lar. E é justamente esse discurso que será incorporado e discutido pela imprensa feminina. Porém, para que a mulher desempenhasse bem o seu papel materno, era necessário educá-la. Assim sendo, de acordo com Bicalho (1989, p. 81), entre os figurinos, as receitas culinárias, os moldes de trabalhos manuais, os conselhos de beleza, os contos e folhetins, os artigos que eram publicados nos jornais femininos defendiam a educação da mulher como condição de sua racional emancipação.

A elaboração de uma nova identidade feminina refere-se principalmente à família e aos papéis de esposa e mãe. Mesmo que se possa observar, como Bicalho aclara (1989, p. 94), um processo de individualização da mulher e de valorização de sua trajetória e de seus projetos pessoais, a biografia feminina continua a girar em torno dos temas, casamento, família e maternidade. Mas por outro lado, a imprensa feminina, ao permitir um diálogo entre as mulheres, forjou uma consciência feminina, a qual se tornou circunstância indispensável ao seu acesso ao campo das reivindicações sociais e políticas.

\section{O JORNAL DAS SENHORAS: PRIMEIRO PERIÓDICO BRASILEIRO PUBLICADO POR MULHERES E DIRECIONADO AO PÚBLICO FEMININO}


O que parece ser a primeira publicação brasileira direcionada ao público feminino e escrita por mulheres foi uma revista literária: o Jornal das Senhoras. Essa revista foi fundada em $1^{\circ}$ de janeiro de 1852, pela argentina Joana Paula Manso de Noronha, no Rio de Janeiro. Esse periódico circulava aos domingos e possuía seções, como moda, literatura, belas-artes, teatro e crítica. Nas suas oito páginas com duas colunas, o público feminino podia encontrar, por exemplo, cartas, versos e traduções de artigos e narrativas ficcionais. De $1^{\circ}$ de janeiro de 1854 em diante, o jornal passa a se chamar Jornal das Senhoras: Jornal da boa companhia.

No artigo de abertura, publicado em $1^{\circ}$ de janeiro de 1852, a diretora apresenta o objetivo editorial do Jornal das Senhoras: "propagar a ilustração, e cooperar com todas as suas forças para o melhoramento social e para a emancipação moral da mulher" (Jornal das Senhoras, 1852, p. 1).

No mesmo texto, intitulado "As nossas assignantes", Joana questiona suas leitoras sobre que bicho de sete cabeças será uma senhora a frente da redação de um jornal. E ela mesma afirma que na França, Inglaterra, Itália, Espanha, Estados Unidos e até mesmo em Portugal, existem muitas mulheres dedicadas à literatura e que colaboram em diferentes jornais. Desse modo, Joana defende a ideia de que a América do Sul não pode ficar estagnada em seus ideais, enquanto o mundo todo avança ao progresso. E assim, ela também convida as mulheres leitoras do Jornal das Senhoras para colaborarem com o periódico:

Por ventura a America do Sul, ella só, ficará estacionaria nas suas idéas, quando o mundo inteiro marcha ao progresso e tende ao aperfeiçoamento moral e material da Sociedade?

Ora! Não pode ser. A sociedade do Rio de Janeiro principalmente, Corte e Capital do império, Metropoli do sul d'America, acolherá de certo com satisfacção e sympathia O JORNAL DAS SENHORAS redigido por uma Senhora mesma. [...]

Ei-nos pois em campanha; o estandarte da ilustração ondula gracioso á briza perfumada dos Tropicos; acolhei-vos a elle, todas as que possuis uma faísca de intelligência, vinde. Confidente discreto das vossas producções literárias, ellas serão publicadas debaixo do anônimo; porém não temaes confiar-mo-las, nem temaes dar expansão ao vosso pensamento; se o possuis é porque é dom da Divindade e aquillo que Deus dá, os homens não o podem roubar. (Jornal das Senhoras, 1852, p. 1). 
O Jornal das Senhoras começou a ser dirigido pela baiana Violante Bivar e Velasco a partir de 4 de julho. Não houve mudanças relevantes na revista depois que Velasco se tornou a nova diretora. Tanto Joana de Noronha quanto Violante publicaram vários artigos sobre a emancipação moral das mulheres. No entanto, quando Violante assumiu a direção da revista, vários artigos sobre religião começaram a ser publicados, tais como "Os prazeres e vantagens da religião" (18 de julho de 1852) e "O sentimento religioso" ( $1^{\circ}$ de agosto de 1852).

De acordo com Vasconcellos (2000, p. 195), Violante Bivar e Velasco dirigiu o Jornal das Senhoras até o encerramento de suas atividades em 1855. Entretanto, ao pesquisarmos nos exemplares da revista, pudemos comprovar que a partir de 12 de junho de 1853, a mesma passou a ser dirigida por Gervasia Nunezia Pires dos Santos Neves.

Sob a direção de Gervazia Neves, os artigos que tratavam explicitamente da emancipação moral da mulher desapareceram da publicação, mas esse tema continuou presente, passando a ser abordado de forma mais sutil, pois as diretoras da revista entendiam por "emancipação moral da mulher" fornecer instrução e educação às mulheres a fim de que elas desempenhassem bem seus papéis de esposa e mãe. Nesse sentido, artigos para instruí-las passaram a ser publicados frequentemente. Um exemplo a ser citado é o artigo "Vantagens do ler", publicado em 31 de julho de 1853, em que os benefícios da leitura são apresentados às leitoras:

\begin{abstract}
A leitura meus amigos!...sabeis vós bem o que é a leitura?! é de todas as artes a que menos custa e a que mais rende. Há livros, que, semelhantes a barquinhas milagrosas, incorruptíveis e inaufragáveis, [sic] nos levam pelo oceano das idades a descobrir, visitar e conhecer todo o mundo, que lá vai: os povos antigos revivem para nós com todos os seus usos, costumes, trajes, feições, crenças, idéias, vícios, virtudes, interesses e relações: a história é a mestra da vida, e as suas lições, ampliação e complemento ao nosso juízo natural. (Jornal das Senhoras, 1853, p. 246).
\end{abstract}

Informações sobre Gervasia Nunezia Pires dos Santos Neves não foram encontradas em nossas pesquisas.

Está claro, então, que o principal objetivo do Jornal das Senhoras, como mencionado acima, era promover a emancipação moral das mulheres brasileiras. Por essa razão, é possível inferir que os artigos e narrativas 
ficcionais publicados na revista estavam relacionados a esse tema. De fato, para considerar o objetivo dela, muitos artigos foram publicados para criticar fortemente a premissa masculina de que as mulheres deveriam ficar longe de tudo que pudesse instruí-las e elevá-las. Para ilustrar essa ideia, podemos mencionar o artigo "Jornal das Senhoras", publicado em 18 de julho de 1852, no qual a autora alega:

Nós que temos hasteado a bandeira - Religião - e emancipação moral da mulher - e convencidas estamos que só esta é a base sobre a qual o edifício social se poderá erguer e suster-se inabalável, de cujo poder nascerão bons filhos, bons cidadãos, bons pais e bons maridos. [sic] (Jornal das Senhoras, 1852, p. 17).

Como podemos perceber, nessa passagem há uma forte ênfase sobre a capacidade intelectual das mulheres. Essa ênfase pode ser explicada pelo fato de que as contribuintes do Jornal das Senhoras acreditavam que elas mulheres e mães - eram as responsáveis pela educação de seus filhos. Por conseguinte, elas mesmas deveriam ser bem educadas e instruídas para conseguirem educar bem os seus filhos, criando assim, bons cidadãos para a sociedade brasileira. Este exemplo nos mostra que os artigos não eram publicados às cegas, mas de acordo com a linha editorial da revista. Como Parker (2000, p. 3) nos permite entender "as intenções de um escritor são apenas parte do significado do texto em um periódico: um texto, em tal cenário, insere-se numa variedade de relações com outros artigos e com preocupações institucionais em curso, os quais dão inflexões sutis para seu significado". ${ }^{3}$ De fato, como se pode perceber, no Jornal das Senhoras, os artigos estavam relacionados de forma geral à promoção da emancipação moral das mulheres brasileiras.

Podemos observar que o Jornal das Senhoras seguiu o propósito corrente de nossos periódicos, que era o de colaborar com a modernização e desenvolvimento cultural da sociedade brasileira, mas com um foco específico: promover uma discussão sobre o melhoramento da educação das mulheres e enfatizar os papéis de mães e esposas por considerá-las responsáveis por

\footnotetext{
3'a writer's intentions are only part of the meaning of the work in a periodical: a work in such a setting enters a variety of relations with other articles and ongoing institutional concerns that give subtle inflections to its meaning". (PARKER, 2000, p. 3 , tradução nossa)
} 
educar e, consequentemente, cooperar para o desenvolvimento da sociedade. O artigo "O filho malcriado", publicado em 27 de fevereiro de 1853, realça o papel das mulheres como educadoras e adota a ideia de que falhar nesse papel seria uma vergonha para elas:

\begin{abstract}
Uma senhora de qualidade tinha um filho, a quem tanto temia desgostar contradizendo a menor de suas vontades, que o menino se tinha tornado um pequeno tirano [...] A senhora ficou tão envergonhada desta cena ridícula, que se corrigiu de sua fraqueza desarrazoada; e daí em diante deu melhor criação ao seu filho. Muitas mães precisariam de uma semelhante aventura. $E$ muitos pais também, porque tenho-os eu visto...que são mesmo uma abóbora d'água. (Jornal das Senhoras, 1853, p. 70).
\end{abstract}

Essa premissa transmitida nesse extrato de "O filho malcriado" também era expressa nas narrativas ficcionais publicadas nessa revista. $\mathrm{Na}$ verdade, essas narrativas traziam instrução sobre a conduta que as mulheres no século XIX deveriam seguir com o objetivo de exercerem com sucesso seus papéis domésticos de mães e esposas.

Essa preocupação do Jornal das Senhoras em tentar formar boas esposas e mães para a sociedade brasileira era percebida pelas leitoras da revista, as quais consideravam sublime a coragem das mulheres que estavam à frente desse periódico em não medir esforços para fornecer leituras que desenvolvessem a inteligência de suas leitoras, para que assim elas conseguissem desempenhar com mais perfeição os seus papéis domésticos. Podemos verificar esse fato através de uma correspondência enviada a redatora, no dia 8 de fevereiro de 1852:

\begin{abstract}
A vossa nobre coragem, senhora, tem me de tal modo impressionado, que não posso deixar de felicitar-vos pela alta consideração que mereceis. Não é porque fosseis a primeira senhora que emprehendeu a diffícil tarefa do jornalismo, nem pelo útil intretenimento que dais ás do nosso sexo sobre modas: não; é pelos sublimes e tocantes pensamentos com que desenvolveis as nossas intelligencias no perfeito conhecimento do que nos cumpre saber para desempenho de nossa missão como filhas, esposas e mães. (Jornal das Senhoras, 1852, p. 44).
\end{abstract}

Em outra correspondência, também publicada no dia 8 de fevereiro de 1852, outra leitora reconhece o benefício que o Jornal das Senhoras tem 
trazido para que as mulheres saíssem do seu estado de vegetação e pudessem exercitar as suas forças:

Nem eu sei como agradecer-lhe este benefício que nos faz á todas, pois que estou certa que todas como eu são unânimes em tributar-lhe votos de gratidão pela empreza que tomou á hombros.

Somos quasi passivas na sociedade, antes quasi que só vegetamos. Bem como a mangueira, crescemos carregamo-nos de folhas, que dão sombra agradável, enchemo-nos de flores odoríferas, que são o encanto dos viventes, produzimos nossos fructos, que o homem colhe sofrego, e depois? Ahi ficamos abandonadas, com a folhagem secca, porque já não damos fructos.

A senhora veio-nos abrir um campo de actividade, em que podemos exercitar as nossas forças, e sahir do nosso estado de vegetação. Como lhe agradeceremos? (Jornal das Senhoras, 1852, p. 44).

Em 30 de dezembro de 1855, o Jornal das Senhoras encerra as suas atividades. Em um aviso às assinantes, publicado nessa data, a redação da revista agradece a colaboração das assinantes durante os quatro anos de existência do periódico. O motivo do encerramento do não é revelado, no entanto, a redação explica que é necessária uma parada para o ano de 1856, e que a publicação da revista retornará em 1857, fato que não se confirma:

Fazemos apenas uma parada, que julgamos necessária, no próximo anno de 1856; e com o favor de Deus o JORNAL DAS SENHORAS reapparecerá em 1857, para prosseguirmos ao honroso fim a que nos proposemos, cultivando com esmero as immarcesciveis flores do caminho tão nobremente encetado pela nossa antiga redactora, a Sra. D. Joanna Paula de Noronha.

Para esse tempo emprasamos todas as nossas assignantes, vós todas Senhoras que briosamente nos tendes ajudado, para que vossa protecção continue a fortalecer nossa árdua e fadigosa tarefa, e o JORNAL DAS SENHORAS seja então o que tem elle até hoje sido para vós cuidadoso e dedicado - o intérprete fiel do que vos é útil e agradável.

Que nossas nobres assignantes nos relevem pois esta deliberação que tomamos, e que esperem pelo dia em que the revelemos a razão de suspendermos hoje a publicação do JORNAL DAS SENHORAS.

A todas e a cada uma em particular dirigimos nossos agradecimentos e um - adeos - até o anno de 1857. (Jornal das Senhoras, 1855, p. 409).

Para concluir, podemos perceber que o que as contribuintes e editoras da revista entendiam por emancipação moral e intelectual da mulher não estava relacionado às mulheres saírem de suas casas e ocuparem cargos públicos e exercerem as mais diversas profissões. $O$ que elas entendiam pela 
emancipação feminina era a mulher ser bem instruída para ter a capacidade de debater sobre os mais diversos assuntos com os homens. E também, elas sendo bem educadas elas conseguiriam melhor instruir os seus filhos, oferecendo assim, bons cidadãos à sociedade brasileira e cidadãos capazes de contribuir com o progresso da civilização. Como Maria Fernanda Bicalho afirma, no século XIX, a imprensa feminina, a excessiva sociabilidade feminina e as opções por prazeres frívolos eram vistos como uma constante ameaça para as virtudes das mulheres (Bicalho, 1989, p. 79). Portanto, como nós podemos entender, no século XIX, a imprensa feminina brasileira tinha como principal objetivo a promoção da educação e a instrução das mulheres, as quais eram indispensáveis para a sua emancipação (Bicalho, 1989, p. 92). Como podemos perceber, o Jornal das Senhoras seguiu essa premissa, já que enfatizou a capacidade da mulher de agir moralmente na sociedade.

\section{REFERÊNCIAS}

BICALHO, Maria Fernanda Baptista. O bello sexo: imprensa e identidade feminina no Rio de Janeiro em fins do século XIX e início do século XX. In: COSTA, Albertina de Oliveira; BRUSCHINI, Cristina (Org.). Rebeldia e submissão: estudos sobre condição feminina. São Paulo, Vértice/Ed. Revista dos Tribunais/Fundação Carlos Chagas, 1989.

JORNAL DAS SENHORAS: modas, literatura, belas-artes, teatros e crítica. Rio de Janeiro, Typ. Parisiense, 1852-1855.

LAJOLO, Marisa; ZILBERMAN, Regina. A leitora no banco dos réus. In: . A formação da leitura no Brasil. São Paulo, Ática, 1998.

MACHADO, Ubiratan. A mulher e a vida literária. In:

A vida literária no Brasil durante o Romantismo. Rio de Janeiro, Ed. UERJ, 2001.

MEYER, Marlyse. Mulheres romancistas inglesas do século XVIII e romance brasileiro. In: EDUSP, 1993.

Caminhos do imaginário no Brasil. São Paulo,

PARKER, Mark. Introduction: the study of literary magazines. In:

Literary magazines and british Romanticism. Cambridge: Cambridge University Press, 2000.

TELES, Maria Amélia de A. Brasil Império (1822-1889). In: Breve história do feminismo no Brasil. São Paulo, Brasiliense, 1999.

VASCONCELLOS, Eliane. Violante de Bivar e Velasco; Joana Paulo Manso de Noronha. In: MUZART, Zahidé Lupinacci. Escritoras brasileiras do século 
XIX. 2. ed. ver. Florianópolis: Ed. Mulheres; Santa Santa Cruz do Sul: EDUNISC, 2000. 